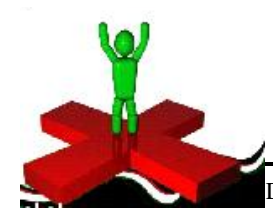

\title{
Impact of diet on patients suffering from coronary heart diseases
}

\section{JYOTSHNA MAYEE SETHI AND PUSPANJALI SAMANTARAY}

See end of the paper for authors' affiliation

Correspondence to :

JYOTSHNA MAYEE SETHI

P.G. Department of Home Science, Berhampur University, GANJAM (ODISHA) INDIA

Email: sethi_jyotshna@ yahoo.com
ABSTRACT : A study on patients suffering from coronary heart diseases has been under taken from cardiology and Medicine department of M.K.C.G. Medical College and Hospital, Berhampur, Odisha belonging to various age groups, sex, income and socio-economic status. This study reveals that diet is one of the contributing factors for coronary heart disease. It was conducted to know the dietary awareness of cardiac patients and the role of hospitals in taking care of the heart patients. In-adequate diet, busy schedule of work and ignorance of nutrient aspects of diet are leading the human beings towards death. Most of the respondents are now becoming more concerned about low-fat diet, exercise, stress management, yoga and meditation. From the investigation it was found that heart disease is no doubt a fatal disease but it can be dealt effectively by taking a balanced and an effective diet, to enjoy the sweetness of life.

How to cite this paper : Sethi, Jyotshna Mayee and Samantaray, Puspanjali (2015). Impact of diet on patients suffering from coronary heart diseases. Internat. J. Med. Sci., 8(1\&2) : 42-46.

\section{KEY WORDS :}

Coronary heart

disease, Hypertension, Atherosclerosis, Dietary pattern 